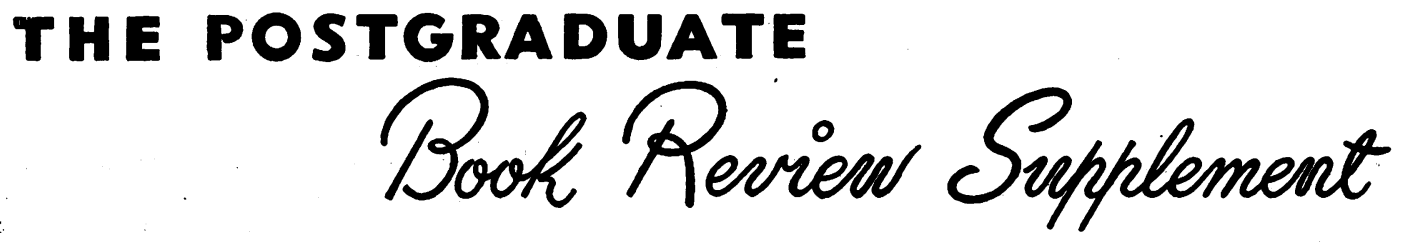

\section{A MANUAL OF PSYCHIATRY}

By K. R. Stallworthy, M.B., Ch.B. 2nd Edition. Pp. 314. Christchurch, New Zealand: N. M. Peryer, Ltd. 1953. 3os.

This is a brief (306 pages), workman-like and compact handbook of psychiatry which covers the whole field in a brisk and practical manner. There is no dead wood. The author writes as an experienced clinician and teacher and does not overweight his text with theory. The book will be useful for the senior student and general practitioner. The next edition will be more useful still to the practising doctor if the author could say a little more about psychotherapy and its scope and limits.

\section{D.O'N.}

\section{CLINICAL ENDOCRINOLOGY}

By Allan William Spence, M.A., M.D., F.R.C.P. Pp. xiii +696 , with 59 illustrations and 2 coloured plates. London: Cassell and Co., Ltd. 1953. 5os.

The author has written this book for ' the general physician and for those aspiring to become clinical endocrinologists.' $\mathrm{He}$ has succeeded in writing a book not only of inestimable value to these classes of practitioner but one which contains large sections of value to neurologists, gynaecologists and to surgeons who operate upon the ductless glands, as well as to many others.

The book, which has been excellently produced by the publishers on high quality paper and freely illustrated with photographic reproductions, cannot be said to be expensive. With the exception of diabetes mellitus it covers the whole field of primary endocrinological diseases as well as referring to more general disorders in which endocrinological factors play, or are thought to play, some part. Preceding each clinical section is a separate chapter dealing with the physiology of the hormones involved. These chapters are relatively short and largely concerned only with that physiology which is essential to a full understanding of the clinical disorders. A brief note of the modes of standardization of hormones is given in each case. Both physiological and clinical sections have historical introductions. Chapters on the clinical features of glandular disorders contain sections on aetiology and pathology, and in each case the problem of $\stackrel{\omega}{\sigma}$ clinical diagnosis, differential diagnosis, laboratory $\bar{C}$ diagnosis and treatment are fully discussed. 3 Sufficient detail is given to enable the physician who is out of touch with this branch of medicine to treat cases without reference to any other literature.

There is a most useful appendix on steroid preparations and their methods of administration. The whole of the bibliography, which extends to 80 pages, is given at the end of the book, references being grouped under chapter headings and subheadings. This is followed by an index of authors. The arrangement of this, as of the whole book, is most convenient for the reader.

Most books of this size and quality are over long in Press and this possibly accounts for the omissioo of reference to a number of very recent develops. ments. The use of neomercazole in the treatment $\&$ क thyrotoxicosis is not mentioned, nor is the value of adrenocorticotrophic hormone in the treatment of hypopituitarism. In the management of unilateral adrenalectomy the author advises the use of deoxycortone acetate and omits reference to the value of cortisone. Total adrenalectomy for Cushing's syndrome in the absence of tumour is also not discussed.

The reviewer has produced these criticisms with difficulty because he conceives it his duty. They do not alter his view that this is an outstanding contribution to medical literature.

Dr. Spence has succeeded in bringing together a vast amount of material and it will be obvious to any reader that the book is the result of a very happy marriage between personal experience and a comprehensive knowledge of the literature of the subject.

N.D.C.

\section{PSYCHOTIC AND NEUROTIC ILLNESSES IN - TWINS}

M.R.C. Special Report Series No. 278

By Eliot Slater, M.D., F.R.C.P., D.P.M. Pp. vi +385 . London: H.M.S.O. 1953. 21s.

This is a study of mental illness in nearly 300 twins carried out by two skilled and critical observers over a period of 13 years. There is much in it to fascinate anyone who tries to disentangle nature and nurture, and the case records in Part. II are 